\title{
Introduction to Teaching Science with Three-dimensional Images of Dinosaur Footprints from Cristo Rey, New Mexico
}

\author{
Valeria V. Martinez, Laura F. Serpa \\ Department of Earth, Environmental, and Resource Sciences, University of Texas at El Paso, \\ 500 W. University Ave., El Paso, Texas, 79968 USA
}

Correspondence to: Valeria V. Martinez (vvguerrero@miners.utep.edu)

\begin{abstract}
In this paper we discuss the use of three-dimensional (3-D) imagery and virtual field trips to teach lower level (i.e., K-14 level) geoscience courses. In particular, 3-D pdfs can be used to either prepare students for, or completely replace, a field trip when logistical problems make the actual trip too difficult to be effective or when some students need an alternative accommodation. Three dimensional images can replace or supplement classroom activities, such as the identification of rocks and minerals from hand samples or the identification of geologic structures from 2-D photographs and limited field observations. Students can also become involved in data collection and processing to further their understanding of photogrammetry and visualization. The use of 3-D imagery can make additional time available to instructors to cover more advanced topics and teach students more about the role of science in geologic research.
\end{abstract}

We use an example from Cristo Rey, New Mexico, where dinosaur footprints and tracks are present but difficult to see in many cases and often in places that are hard to access for many people. At this site, approximately 10,000 photographs were collected and processed as 3-D images to show one approximately $72 \mathrm{~m}^{2}$ area of known footprints. However, we also conducted some very simple digital manipulations of the images that allowed us to identify new footprints and tracks that were not apparent when viewed in the field. The photographs and 3-D images have been donated to the Insights museum that owns the fossil site and they are now being used to develop educational materials and lessons for the nearby communities.

\section{Introduction}

25 The current pandemic has changed education in many ways, but few areas of science education have been impacted as much as the geological sciences where field observations and trips are a significant part of most geoscience curriculums. During the pandemic many universities replaced field trips and exercises with a variety of virtual field experiences (Rotzien et al., 2021) despite some prior faculty reticence to the use of computer-based tools for field mapping classes and other field activities. In addition, prior to the pandemic there was a growing trend at many universities and K-12 schools in the U.S. to eliminate or restrict field activities because of administrative concerns about student liability, cost and, in some cases, the lack of faculty able and/or willing to teach field-based classes on a regular basis. It is our opinion that the pandemic will be a major factor in a permanent decrease in the number of field-based geology activities in U.S. universities. Indeed, we expect that field observational geology will become virtual for nearly all pre- or early-college students who are not majoring in a geoscience.

35 One critical question regarding the changing emphasis on field experiences (Whitmeyer et al., 2020) in geoscience education is whether field-based activities are truly essential and where might they be most valuable. The authors of this paper are experienced geoscientists with considerable field experience, but we contend that there are some significant benefits to the use of technology in geoscience education. We argue that non-majors at universities and students in the K-12 system may learn more from virtual field activities than they might learn from actual field-based observations. In particular, we see the use of 3- and 4-dimensional photogrammetry models and videos, as well as 
many other developing technologies like artificial intelligence and large-scale statistical methods (Whitmeyer et al., 2019), have an educational advantage over field work because they are more relevance to many students. In addition, the incorporation of virtual activities and lessons in a modern textbook should provide more time for discussions of what geoscience researchers actually do and why that is important science. To test this concept, we are working with a local museum to develop educational materials on dinosaur footprints and that effort is described below.

\subsection{Study Area}

Cristo Rey, New Mexico (Figure 1) is the site of numerous Cretaceous dinosaur footprints and trackways that are particularly difficult to recognize and map (Kappus and Cornell, 2003; Kappus et al., 2011), because weathering patterns obscure or mimic many of the fossils and the locality experienced Tertiary uplift and tilting that deformed the site and made the terrain difficult to navigate. The fossil site is located adjacent to the U.S. - Mexico border near the cities of Las Cruces, NM and El Paso, TX and this makes it a potentially valuable local education resource. The donation of the land to the Insights Museum in 2011 opened the site to educational groups and the development of exhibits but that work is still in early development. In an effort to preserve as much information as possible on the dinosaur footprints and to provide students and teachers with a non-invasive way to study the fossils, Martinez (2016) created a detailed high resolution photographic record of a portion of the site and used that data to build 3-D images of the ground surface. Those images not only provide a record of the site but also led to the identification of several new footprints and fossils based on digital manipulation of the images.

The use of 3-D models to study fossils is a relatively recent technique (Bates et al., 2008, Adams et al., 2010, Remondino, et al., 2010, Tavani, et al., 2014) that has an advantage over methods such as paper mapping, plaster casts or collecting samples because it is nondestructive and can be easily shared with a wide audience. Our preliminary study of the images shows numerous Cretaceous Therapod, Iguanodon and Ankylosaurus footprints (Figure 2) previously identified by Kappus et al. (2011) as well as new footprints and trails of those dinosaurs that were not previously recognized. These images were donated to the Insights Museum and we are helping to develop educational resources for the local community to encourage studies of the fossils.

65 Our educational activities focus on both methodology and fossil identification for several age groups. We are focusing on the use of 3-dimensional images that can be easily used in the classroom and manipulated by students with minimal expense or expertise. The fossil identification will follow traditional lessons plans that include the identification of dinosaurs based on their footprints, estimating the size and speed of a dinosaur based on the measured stride (Thulborn, 1990) and looking at dinosaur activities in relationship to their environmental setting (Lockley, 1986; 2011). We anticipate that the Insights Museum will expand on our preliminary work but we will work closely with them to develop some initial lessons based on our own experience of discovery at the site.

\subsection{Geologic Background}

The first fossil footprints, identified as Cretaceous therapod footprints, were discovered by Kappus and Cornell (2003). The footprints are in Cretaceous sedimentary deposits that were intruded by a Tertiary trachyandesite dome (Lovejoy, 1976). The dinosaur tracks are located primarily in the upper sandstone of the Anapra formation which is a massive cross bedded arkosic sandstone varying in thickness from 1-2 $\mathrm{m}$ and interbedded with grey and purple shale (Lovejoy, 1976). These sedimentary layers indicate that the Cretaceous environment in this area was a shallow sea (Kappus, et al., 2011).

\subsection{Methods}

80 Most of the initial research on the Cristo Rey tracks consisted of field notes, photos, and drawings (Kappus and Cornell, 2003; Kappus et al., 2011). More recently, technology has become available to create 3-D visualizations of geologic units and this is changing the way fossils are studied (Remondino et al., 2010). Kappus, Hurtado, and Aldouri 
(personal communication, 2016) used LiDAR to record the Cristo Rey footprints to produce the first 3D images of the site. The resulting anaglyph 3D images require blue and red glasses to see and cannot be easily manipulated on a computer, but they provide the inspiration for continued work in this area.

\subsection{Data Collection}

The original goal of this project was to create a digital record that could be used in educational programs and research that did not require field visits in all cases. The materials needed for this project can be easily obtained and used with teachers and their students (e.g., Fleming and Pavlis, 2018). However, we did use materials in this project that may not be readily available to most teachers. For example, we used a Nikon Camera series D3100 digital single-lens reflex (DSLR) camera for our photography and Agisoft Photoscan Pro ${ }^{\mathrm{TM}}$ and ENVI ${ }^{\mathrm{TM}}$ software for processing and data analysis which may not be affordable for most teachers. However, a cell phone camera and several inexpensive and free software packages are available if the data set is kept small.

We collected approximately 10,000 photographs and reduced the number to 7600 photographs using a grid system that was approximately 9 meters across in the $\mathrm{X}$ direction and 8 meters across in the $\mathrm{Y}$ direction (Figure 3 ). Four people were needed for the data collection with one located at position $(0,0)$ to establish the origin position, one person measuring the $\mathrm{X}$ coordinates with a measuring tape, another measuring the $\mathrm{Y}$ coordinates with a second measuring tape (Figure 4), and one using a meterstick to precisely mark grid points on the outcrop using temporary adhesive stickers labeled with the point's coordinate number (Figure 5). The lead author, Martinez, developed the grid system and supervised the grid measuring process and took all the photographs. At each grid intersection, a suite of photographs was taken at a distance of $\sim 1 \mathrm{~m}$ from the surface with the camera directed into the adjacent grid areas. This was done at each grid position until all 4 corners had been occupied for photography. The total number of pictures taken at each grid position depended on the surface texture and variations in the surface of the target. For example, if there were a lot of variations in the target surface, then more pictures were taken in order to capture sufficient details for subsequent modeling.

\subsection{Data Processing}

The images were processed using the structure from motion (SfM) photogrammetry technique (Westoby et al., 2012). The photogrammetric processing was done using Agisoft Photoscan Pro ${ }^{\mathrm{TM}}$ software to create a 3D model from the photos. Each set of photos for a single grid section was processed individually to form a $1 \mathrm{~m} x 1 \mathrm{~m}$ "chunk" (Anon., 2016) because the data set was too large to process the entire set as a single unit. Once all the chunks were created, they were arranged to form larger chunks, starting with grid positions $(0,0)$ and $(0,1)$. In this fashion, the chunks were iteratively aligned and merged to make progressively bigger chunks.

In 2015-2016 we were limited by available computing power and did not have sufficient RAM and CPU power to create a single model for the entire outcrop. For that reason, we chose to work on a subset of our data in an area where Kappus et al. (2011) found the most dinosaur footprints (Figure 3). In early 2021 we used Pix $4 D^{\text {TM }}$ software to reprocess some of the data for this paper and have had some success but have not yet been able to produce a single model of the entire area. There is insufficient overlap of photos between some of the grid areas to use the SfM software to completely merge all of the images into a single model because the method we used to collect data focused on coverage within each grid area but not on the connectivity between grid areas.

120 Besides the problems with the lack of overlap between grid sections in many of our photos, the camera was also too close to the surface to accurately capture all of the topographic relief in the region. We also did not have position information for the individual photos so it was not possible to georeferenced the data (Brush etal, 2019). This was our first effort to collect photogrammetry data and we recognized our mistakes and subsequently collected sUAV (drone) and Lidar which we will compare to our high-resolution photography in the near future. Despite the problems 

sections independently or in small groups. This provides us with an excellent educational data set that students and teachers can access freely and learn more about fossils and photogrammetry techniques.

\subsection{Education Applications}

The photographs described in this paper make up our initial donation to the Insights Museum to provide a permanent record of the fossil site. In addition, we will provide 3-D images made with the SfM software (cloud data) that can be distributed in a variety of formats. The basic format for the cloud data as seen in Figure 6 and Figure 7 is LAS which can be manipulated using software like Cloud Compare ${ }^{\mathrm{TM}}$ which is freeware and has the ability to make depth measurements and comparisons with other data sources and many other relevant applications. In addition, we can produce 3-D pdf files (Figure 8) that can be opened using software from Adobe ${ }^{\mathrm{TM}}$ on most standard laptop computers and tablets. The 3-D pdf files can be manipulated in a number of ways to help students recognize fossils.

The original fossils identified by Martinez (2016), were from a 3-D pdf of a small set of photos where she removed the color from a 3-D pdf image and found that the weathering patterns in the rocks obscured the footprints and distracted from recognition of the fossil relief. This was first observed by simply turning the 3-D pdf over and looking at the back side which had no color at that time and showed the footprint as a high area rising above the background rock. Subsequent mapping of depth variations at a small scale combined with color removal made more footprints and tracks apparent in the site as shown in Figure 6 and Figure 7.

\subsection{Fossil Identification}

Our experience suggests that most students first learn about fossils by seeing a few examples, usually photographs in a textbook, and learning to recognize some basic characteristics of a fossil that can be used to identify the source. For students living near a fossil locality this may also involve a field trip to collect fossils. However, some fossil localities are rapidly disappearing because the fossils have all been collected. Cristo Rey fossils have been heavily collected and most remaining fossils are in hard to access areas that may not be safe to visit for young people with little or no field experience. We also hope that the remaining fossils will not be collected so that scientific studies of the footprints can be conducted well into the future.

Figure 6 and Figure 7 show images from a part of the area that includes two footprints and are photographs of the actual 3-D dense cloud models. A 3-D pdf of that area is shown in Figure 8 that should be manipulatable with Adobe Acrobat Pro ${ }^{\mathrm{TM}}$ with 3-D enabled but may take a few minutes to open. Readers and students can change the orientation and tilt of the 3-D image to bring out varying views of the depth and highlight the mud ridges. We have also included a preliminary instructional video (Martinez lecture) that provides students with more information about the dinosaur site and how to identify the footprints. The image on the left side of Figure 6 shows a view of what would be seen in the field if the lighting is good. However, because the students will have a 3-D image (Figure 8) to look at, they will be able to manipulate it with a computer, tablet, or smart phone in ways that are not available to the field observer. One of the first things we did with the images when we started this project was to turn the 3-D pdf image over and look at the back side where footprints that are depressed in the top side pop out as raised impressions on the back side of the image as shown on the right side of Figure 6.

The footprints may be difficult for students to find initially because there is a lot of color variations in the rocks. However, we can change the colors in the computer image also; Figure 7. shows the same images as shown in Figure 7 but the true colors are replaced by two tone color variations that change intensity with depth. In this format, the most visible footprint is easily seen as a depressed area that is darker brown than 
the surrounding, yellow high areas in the right-hand image and as a light area in the backside of the image where we used grey tones. Students can experiment with their image colors, orientation or scale to find a representation that helps them to visualize the footprints and learn something about how visualization works in the process.

Once students learn to find the footprints in the image, they can compare them to published information (e.g. Thulborn, 1990) to identify the dinosaurs that made the prints. Students can also measure the prints and if there are sufficient prints, they can measure the stride of the dinosaurs to make an estimate of the sizes of the dinosaurs. Some additional lessons that can be included might be to look at how mud was apparently pushed away from the footprint and compare that to how a human footprint changes when a person runs compared to a walking person's footprint in mud. In some cases, students might consider how a footprint would look if the dinosaur were pushing along in shallow mud while swimming. This would provide additional information about the environment and lifestyle of the dinosaurs (Boggs Jr., 2012).

This data can also give teachers a chance to develop their students' critical thinking skills. Cristo Rey is located in a desert region, but the dinosaurs clearly lived in a shallow water environment in our area which could open a discussion on climate change (Dalla Vecchia, 2008), for example. Comparing how the students might displace mud in a wet environment and observing similar features in the dinosaur footprints could create a better understanding of how science works and builds understanding of the processes we study. In addition, some footprints overlap other footprints which opens discussions of the time relationships and whether one of the types of dinosaurs found in our area could have lived there at a much earlier time than another. This would be an excellent exercise for the students to explore with the entire data set.

\subsection{Photogrammetry}

In addition to learning about fossils, students can learn more about the process of visualization and making 3-D images from the more than 7000 photos available from the Insights Museum. There are inexpensive or free software packages available to work with smart phone images to build 3-D models (e.g., Fleming and Pavlis, 2018). This gives students an excellent opportunity to learn more about how humans perceive depth and dimensionality, for example. Where more sophisticated software is available, students can work on building a geologically accurate representation of the Cristo Rey fossil sites. This should also give students an understanding and the necessary skills to look at rocks and minerals, for example, or any number of subjects in 3-D which is likely to be common in their future regardless of the career they chose.

\subsection{Conclusions}

Introductory Geology is often taught using a small set of rock and mineral samples in a lab often combined with field excursions that may be taught by graduate students with little training in the broad range of topics covered in the lab. Introductory physical geology textbooks and lab manuals typically devote 4 to 5 chapters to rock and mineral identification and a chapter on, for example, structural geology that uses photographs or sketches where a student is expected to memorize the names of the features in the image. One reason for this is that Geoscience is often not taught at the high school level and because there are relatively few geoscience majors entering the universities as freshmen, departments try to recruit majors from the students who choose to take a geology course to meet a science elective or because their major requires it. Those students are often not well prepared for a more rigorous science course and departments may focus on 
making their course interesting, informative, and relevant but usually not as difficult as, for example, an introductory Physics or Chemistry course. We compare this to students taking an introductory university biology class that is based almost entirely on pictures, dissecting animals, and field trips to collect plants and bugs. Many students might enjoy such a class, but it is not likely to inspire many of them to become research scientists when this method is used at the university level.

We are not suggesting that field experiences or working in a lab with samples is not valuable, particularly in more advanced classes, but many universities train teachers who only take one introductory geology class before they teach a class in the K-12 system. As a result, few students learn much about what makes geology a science or arrive at universities with the intent of becoming a geologist. We believe the increasing availability of 3-D images that can show a wide range of scales and include videos on a tablet or cell phone frees up an instructor and textbook to explain the processes behind the images and how a geologist studies the Earth using sophisticated equipment. A prime example would be figure 10 which is a great example of extracting a specific field sample digitally and sharing it in compatible software programs, such as Word and PowerPoint. We also have the flexibility of linking specific images and lessons from Word documents 220 to PowerPoint lessons (VM1.pptx) to aid students in viewing the lesson digitally. Because the data are digital, students can compile large data sets and analyze them, make detailed measurements, and explore properties of materials in much the same way we used color and depth to enhance dinosaur footprints at Cristo Rey.

The use of 3-D pdf files in a classroom or textbook is just the first of many possible uses of digital data and software to give students a sample of the tools that many researchers use regularly. The tools that we used to generate the 3-D pdf files from the photographs can easily be accessed and manipulated on a smart phone or tablet. The same methods can be applied to rocks and minerals, outcrops, and large-scale geologic features. Rotzien et al (2021) used 3-D Google Earth images to prepare students for field mapping. Google Earth is often used in labs and introductory classes and textbooks so this is not a new idea. However, 230 Google Earth is not usually high enough resolution to see the detailed outcrop images or identify rock types or fossils. It cannot be manipulated with other software so it is not the ideal tool for the lessons we think students should have. We believe the primary outcome of using higher level technology in introductory classes is that students will see geoscience more as a real science than as something that should be left to pre-university level courses with teachers who do not see the subject as real science.

235 We would like to see a change in how introductory university geoscience is taught with more emphasis on understanding processes and associations through the use of a broad range of high resolution, digital imagery. Exercises could involve looking at a variety of characteristics from one area or seeing the same geologic feature in different places and varying stages of development, for example. Every university could develop virtual field trip activities using digital data from their local area so that students can learn about why geology is relevant to their lives. Software, such as StraboSpot (Walker et al, 2019), are becoming more available and could provide the tools for rewriting our non-majors' textbooks so that students get a more realistic idea of how the earth works and what a geoscientists does. The possibilities for developing virtual class materials is growing rapidly and we think now is the time to begin to bring it into the classroom. 


\section{References}

Adams, T.L., Strganac, C., Polcyn, M.J., and Jacobs, L.L., High Resolution Three-Dimensional LaserScanning of the Type Specimen of Eubrontes (?) glenrosensis Shuler, 1935, from the Comanchean (Lower Cretaceous) of Texas: Implications for Digital Archiving and Preservation. Palaeontologia Electronica Vol. 13, Issue 3; 1T:11p; http://palaeo-electronica.org/2010_3/226/index.html, 2010.

Anon., Agisoft PhotoScan User Manual: Professional Edition, https://www.agisoft.com/pdf/photoscan-pro, 2016.

Bates, K. T., Manning, P. L. \& Hodgetts, D., Three-Dimensional Modelling and Analysis of Dinosaur Tracks. Paleontology, pp. 999-1010, 2008.

Boggs Jr., S., Principles of Sedimentology and Stratigraphy, Upper Saddle : Pearson, 2012.

255 Brush, J.A., Pavlis, T.L., Hurtado, J.M., Jr., Mason, K.A., Knott, J.R., and Williams, K.E., Evaluation of field methods for 3-D mapping and 3-D visualization of complex metamorphic structure using multiview stereo terrain models from ground-based photography: Geosphere, v. 15, no. 1, p. 188-221, https://doi.org/10.1130/GES01691.1. 2019.

Dalla Vecchia, F. M., The impact of dinosaur palaeoichnology in palaeoenvironmental and palaeogeographic reconstrucions: The case of the Periadriatic carbonate Platform. ORYCTOS, pp. 89-106. 2008.

260 Fleming, Z. and Pavlis, T.: An orientation based correction method for SfM-MVS point clouds--Implications for field geology, J. Struct. Geol. 113, 76-89, https://doi.org/10.1016/j.jsg.2018.05.014, 2018.

Kappus, E. \& Cornell, W. C., A New Cretaceous Dinosaur Tracksite in Southern New Mexico. Palaentologia Electronica, 2003..

Kappus, E. J., Lucas, S. G. \& Langford, R., Cerro de Cristo Rey Cretaceous Dionsar Tracksites, Sunlad Park, New Mexico, USA, and Chihuahua, Mexico. New Mexico Museum of Natural History and Science, 2011.

Lockley, M. G., The Paleobiological and Paleoenviromental Importance of Dinosaur Footprints. Society for Sedimentary Geology, 1986.

Lockley, M. G., New Mexico Museum of Natural History and Science. Therapod- and Prosauropod-Dominated Ichnofaunas from the Navajo-Nugget Sandstone (Lower Jurassic) at Dinosaur National Monument: Implications for Prosauropod Behavior and Ecology, pp. 316-320, 2011.

Lovejoy, E. M., Geology of Cerro Rey Upflit, Chihuahua and New Mexico. New Mexico Institute of Mining \& Technology, 1976.

Martinez, V. V., Reconstructing Dinosaur Foot Tracks and Identifying New Dinosaur Footprints using Structure from Motion Photogrammetry. M.S. Thesis, University of Texas at El Paso, El Paso, Texas, 2016.

275 Pavlis, T.L. and Mason, K.A., The new world of 3D geologic mapping: GSA Today, v. 27, no. 9, p. 4-10, https:// doi .org /10 .1130/GSATG313A .1 , 2017.

Remondino, F. et al., Ichnology-Recovery Digital 3D Models of Dinosaru Footprints. The Photogrammetric Records, pp. 266-282, 2010. 
Rotzien, J. R. Sincavage, R., Pellowski, C., Gavillot, Y., Filkorn, H., Cooper, S., Shannon, J., Yildiz, U., Sawyer, F., Uzunlar, N., Field-Based Geoscience Education during the COVID-19 Pandemic: Planning, Execution, Outcomes, and Forecasts, GSA Today, v. 31, https://doi.org/10.1130/GSATG483A.1. CC-BY-NC, 2021.

Tavani, S. et al., Building a virtual outcrop, extracting geological information from it, and sharing the results in Google Earth via OpenPlot and Photoscan: An example from the Khaviz Anticline (Iran). Computers \& Geoscience, pp. 4453,2014 ..

285 Thulborn, T., Dinosaur Tracks. Chapman \& Hall. London, New York, Tokyo, Melbourne, Madras ISBN 041232890 9, 410 p.,1990.

Walker, J.D., Tikoff, B., Newman, J., Clark, R., Ash, J., Good, J., Bunse, E.G., Moller, A., Kahn, M., Williams, R.T., Michels, Z., Andrew, J.E., and Rufledt, C., StraboSpot data systems for structural geology, Geosphere, v. 15, https://doi.org/10.1130/GES02039.1, 2019.

290 Westoby, M. J. et al., Structure-from-Motion photogrammetry: A low-cost, effective tool for geosicence applicaitons. Geomorphology, pp. 300-314, 2012.

Whitmeyer, S.J., Pyle, E.J., Pavlis, T.L., Swanger, W., and Roberts, L., Modern approaches to field data collection and mapping: Digital methods, crowdsourcing, and the future of statistical analyses, Journal of Structural Geology, v. 125, 29-40, https://doi.org/10.1016/j.jsg.2018.06.023, 2019.

295 Whitmeyer, S. J., Atchison, C., and Collins, T.D., Using mobile technologies to enhance accessibility and inclusion in field-based learning, GSA Today, v. 30, https://doi.org/10.1130/GSATG462A.1, 2020. 
Figure 1 Map of the region with an insert (@Google Earth, 2021). The red box in the google earth image shows the study area in Cristo Rey, New Mexico.

Figure 2. A general foot print shapes of the 3 types of Cretaceous dinosaur footprints identified (Kappus and Cornell, 2003; Kappus et al., 2011; Martinez, 2016). A. is an Anklyosaurs, B. is an Iguanadon, and C. is a Theropod.

Figure 3 Grid layout used to take photographs. The grid spacing is 1 meter and photos were taken from each grid intersection with a camera aimed into the target grid space. The shaded area shows the area we processed for this study and the heavy dashed line outlines the map area from Kappus et al.(2011).

Figure 4 The grid system used in this study was based on 2 metric tape measures laid out perpendicular to each other to establish the locations for photographs. The position of the individual grid intersections at 1 meter spacing was marked as shown in Figure 5.

Figure 5 Showing the mark that indicates the intersection of two 1-m spaced grid lines in the survey area.

Figure 6 Front and Back view of Cristo Rey 3-D pdf image from grid sections 3,4 to3,5 and 4, 4 to 4, 6 . Each image occupies an area of approximately 2 meters by 2 meters. Image $A$ shows what a field observer would see in the fossil locality and B shows the same image as $A$ but reversed to show the back side of the fossil image which a field observer would not see.

Figure 7 Shows the same images shown in figure 6 but the natural color of the images has been replaced by colors that vary with depth. The red dashed line shows the location of a fracture imaged in the model. The red dashed line shows the location of a fracture in the rocks and the footprints are outlined in this image.

Figure 8 is a 3-D pdf of Cristo Rey sections 4-5 and 4-6. It should be opened using Acrobat Pro or similar software with 3-D viewing enabled. It may take a few minutes to open but the reader should be able to manipulate the image by moving the cursor over it when it is open. 
https://doi.org/10.5194/gc-2021-15

Preprint. Discussion started: 11 June 2021

(c) Author(s) 2021. CC BY 4.0 License.

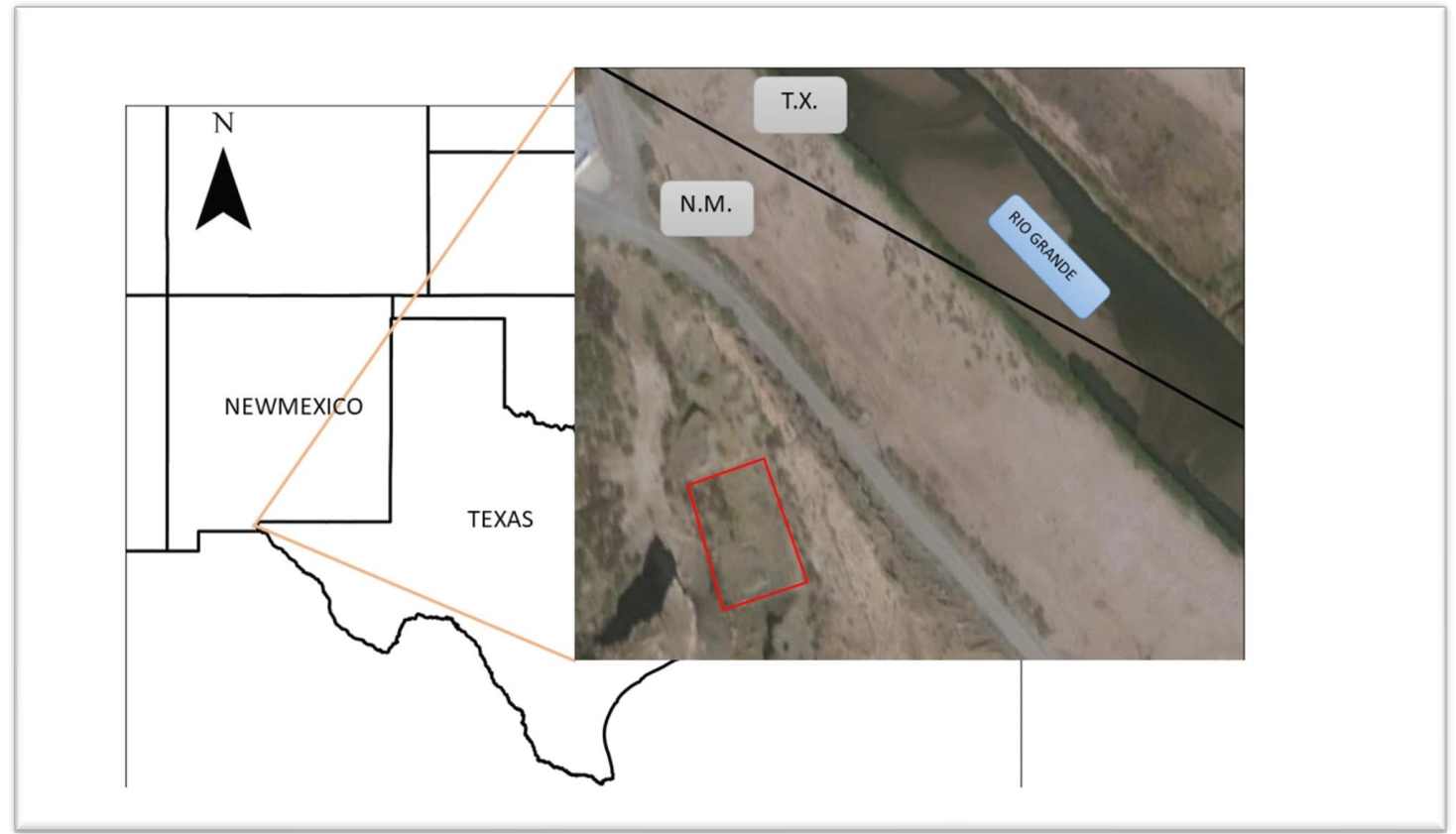

Figure 1 Map of the region with an insert (@Google Earth, 2021). The red box in the google earth image shows the study area in Cristo Rey, New Mexico. 
https://doi.org/10.5194/gc-2021-15

Preprint. Discussion started: 11 June 2021

(c) Author(s) 2021. CC BY 4.0 License.

Discussions

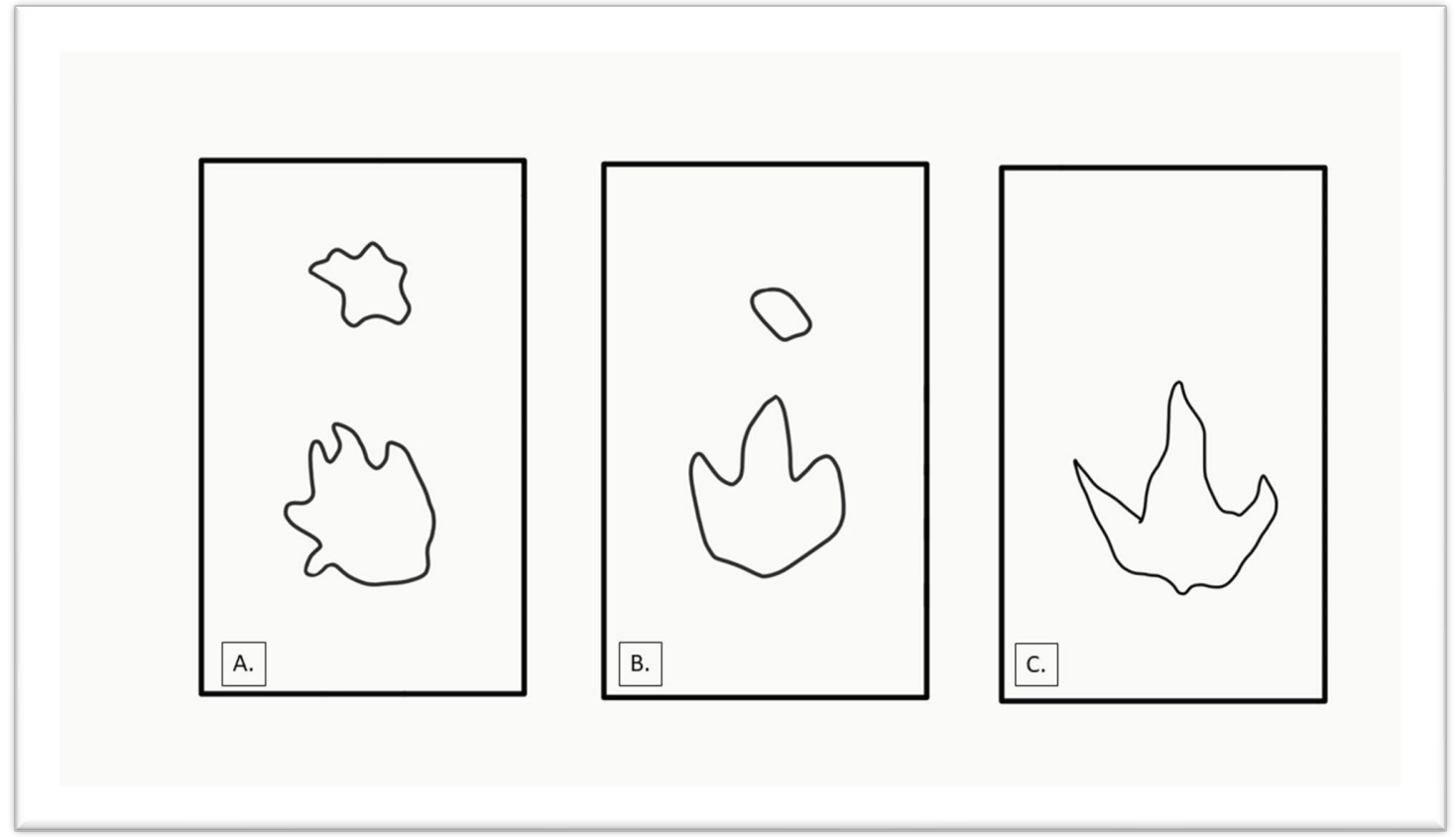

Figure 2. A general foot print shapes of the 3 types of Cretaceous dinosaur footprints identified (Kappus and Cornell, 2003; Kappus et al., 2011; Martinez, 2016). A. is an Anklyosaurs (outline modified from (Kappus, et al., 2011) and (Martinez, 2016)), B. is an Iguanadon (outline modified from (Kappus, et al., 2011) and (Martinez, 2016)), and C. is a Theropod (outline modified from (Kappus, et al., 2011)) 
https://doi.org/10.5194/gc-2021-15

Preprint. Discussion started: 11 June 2021

(c) Author(s) 2021. CC BY 4.0 License.

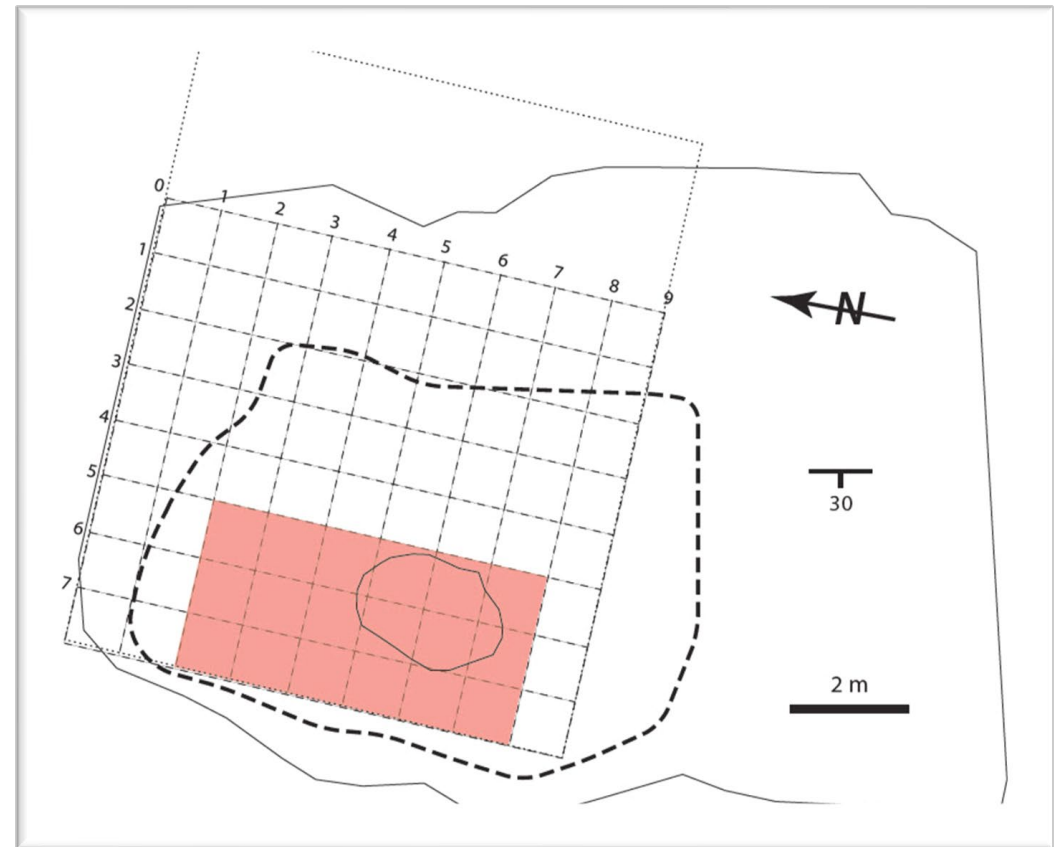

Figure 3 Grid layout used to take photographs. The grid spacing is 1 meter and photos were taken from each grid intersection with a camera aimed into the target grid space. The shaded area shows the area we processed for this study and the heavy dashed line outlines the map area from Kappus et al.(2011). 
https://doi.org/10.5194/gc-2021-15

Preprint. Discussion started: 11 June 2021

(c) Author(s) 2021. CC BY 4.0 License.

(c)

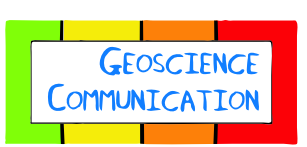

Discussions

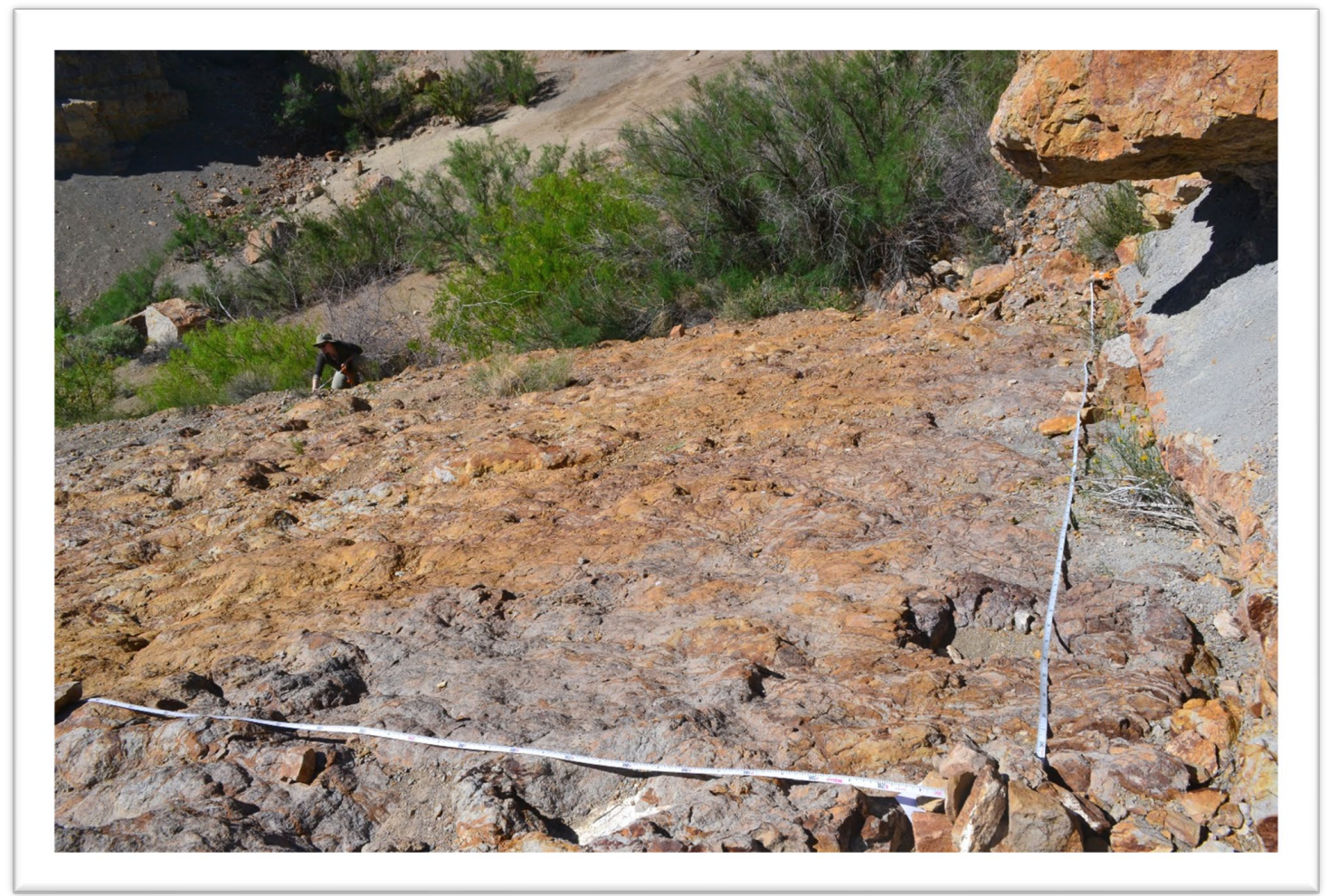

Figure 4 The grid system used in this study was based on 2 metric tape measures laid out perpendicular to each other to establish the locations for photographs. The position of the individual grid intersections at 1 meter spacing was marked as shown in Figure 5. 
https://doi.org/10.5194/gc-2021-15

Preprint. Discussion started: 11 June 2021

(c) Author(s) 2021. CC BY 4.0 License.

(c) (i)

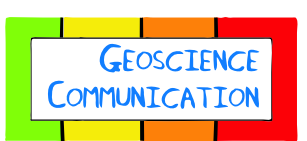

Discussions

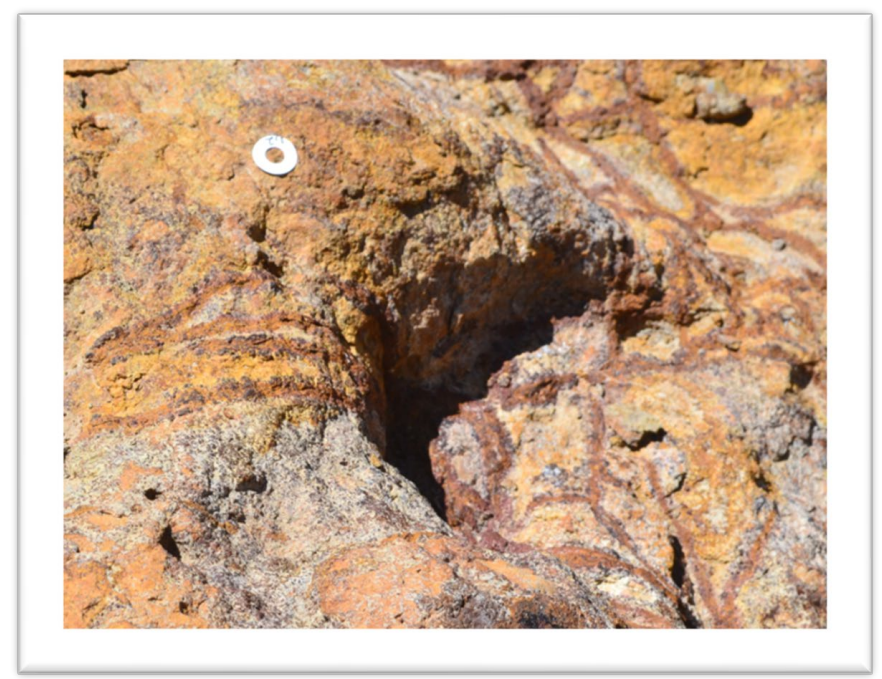

Figure 5 Showing the mark that indicates the intersection of two 1-m spaced grid lines in the survey area.

350

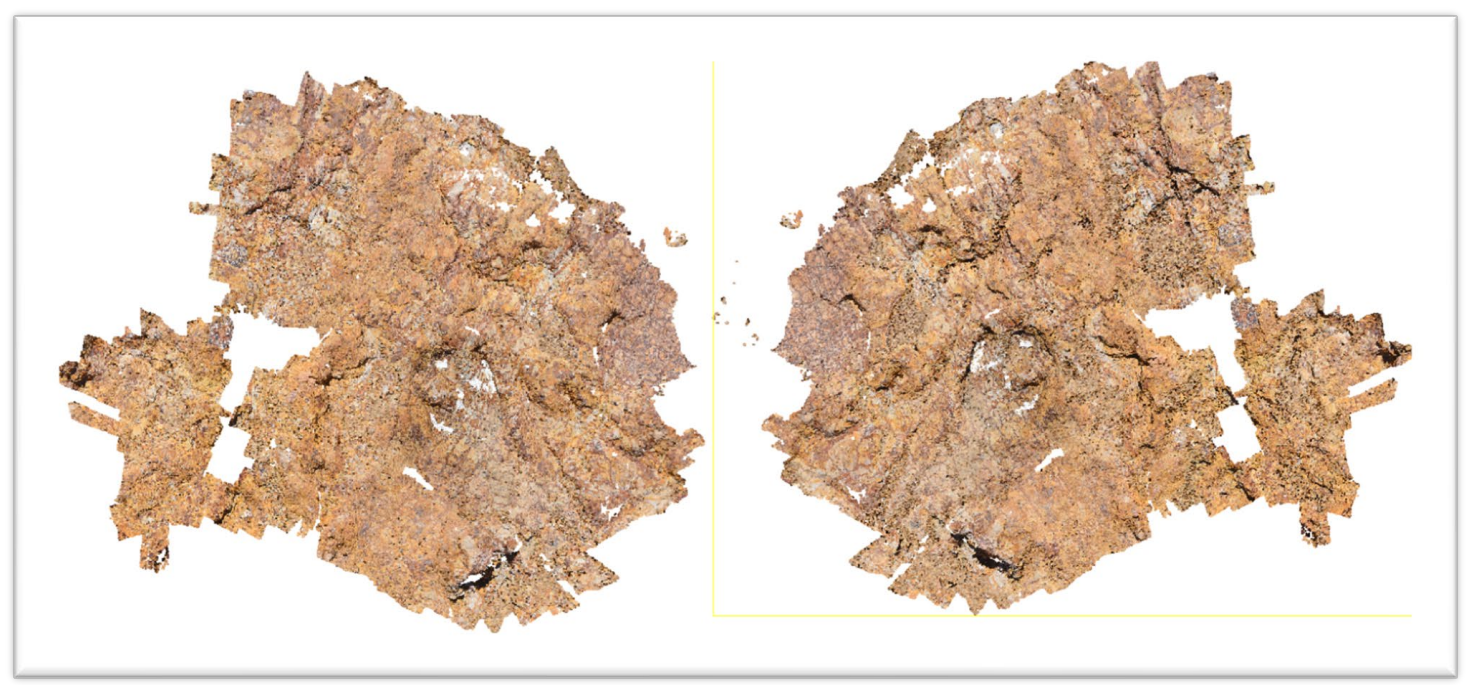

Figure 6 Front and Back view of Cristo Rey 3-D pdf image from grid sections 3,4 to3,5 and 4, 4 to 4, 6. Each image occupies an area of approximately 2 meters by 2 meters. Image A shows what a field observer would see in the fossil locality and B shows the same image as $A$ but reversed to show the back side of the fossil image which a field observer would not see. 
https://doi.org/10.5194/gc-2021-15

Preprint. Discussion started: 11 June 2021

(c) Author(s) 2021. CC BY 4.0 License.
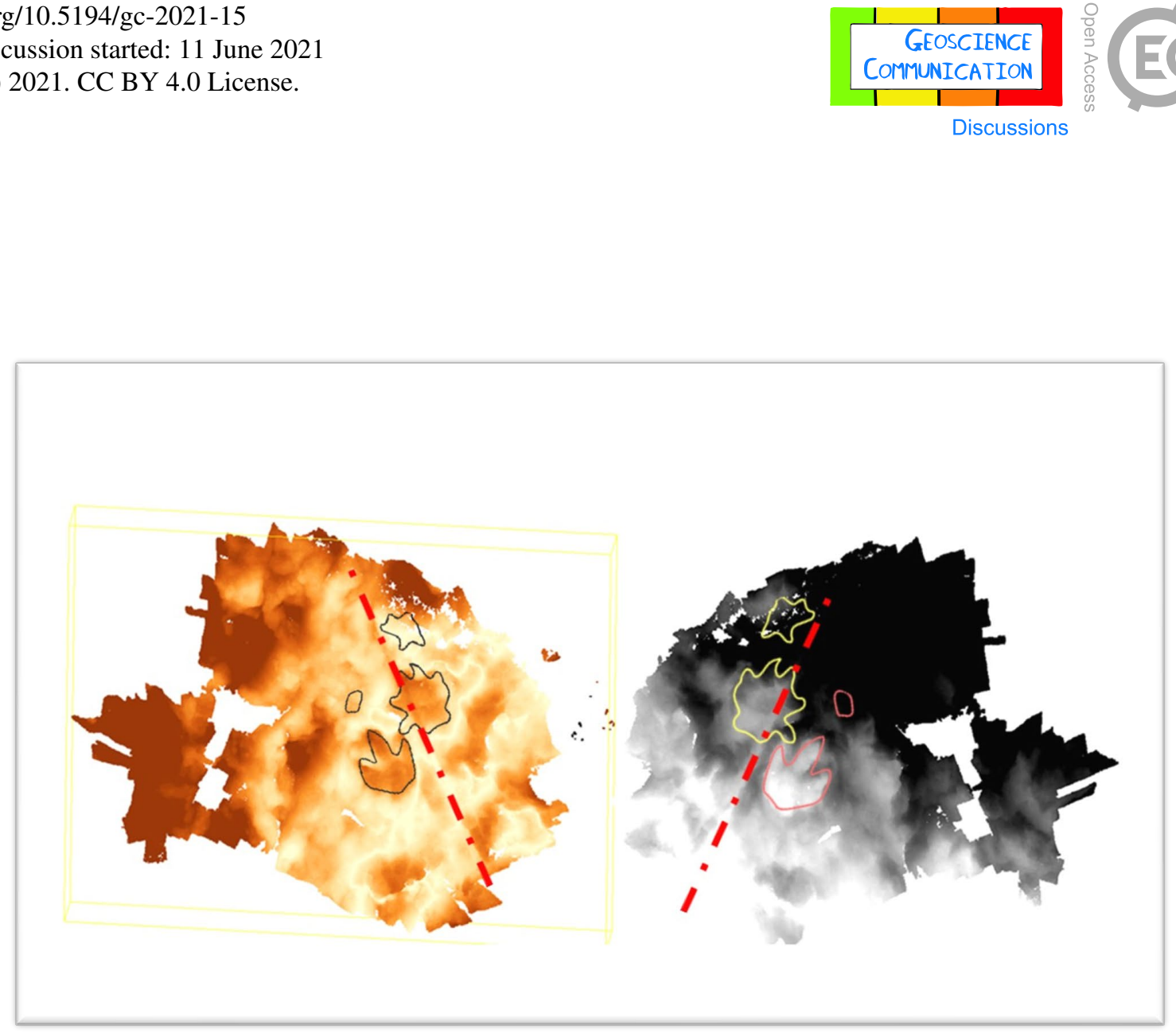

Figure 7 Shows the same images shown in figure 6 but the natural color of the images has been replaced by colors that vary with depth. The red dashed line shows the location of a fracture imaged in the model. The red dashed line shows the location of a fracture in the rocks and the footprints are outlined in this image. 
https://doi.org/10.5194/gc-2021-15

Preprint. Discussion started: 11 June 2021

(c) Author(s) 2021. CC BY 4.0 License.

\section{cristo_4-4_4-6_simplified_3d_mesh}

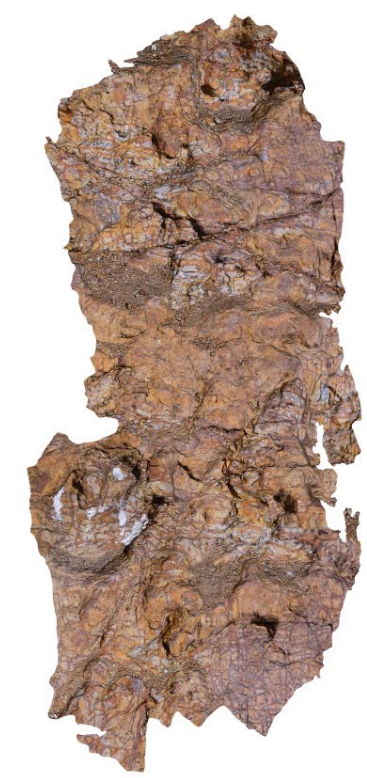

Figure 8 is a 3-D pdf of Cristo Rey sections 4-5 and 4-6. 